\title{
Regulatory Assessment Reason Code
}

National Cancer Institute

\section{Source}

National Cancer Institute. Regulatory Assessment Reason Code. NCI Thesaurus. Code C94053.

A coded value specifying the rationale for a regulatory designation. 